\title{
Controlling the morphology of dynamic thia-Michael networks to target pressure sensitive and hot melt adhesives
}

Katie M. Herbert ${ }^{1}$, Neil D. Dolinski ${ }^{1}$, Nicholas R. Boynton ${ }^{1}$, Julia G. Murphy ${ }^{2,3}$, Charlie A. Lindberg', S. J. Sibener ${ }^{2,3}$, and Stuart J. Rowan 1,2,4,*

${ }^{1}$ Pritzker School of Molecular Engineering, ${ }^{2}$ Department of Chemistry, and ${ }^{3}$ James Franck Institute, University of Chicago, Chicago, IL 60637, United States.

${ }^{4}$ Chemical Science and Engineering Division and Center for Molecular Engineering, Argonne National Laboratory, 9700 S. Cass Ave., Lemont, IL 60434, United States.

* to whom correspondence should be addressed: stuartrowan@uchicago.edu

\section{Table of Contents}

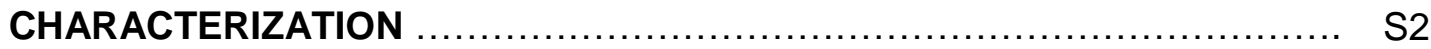

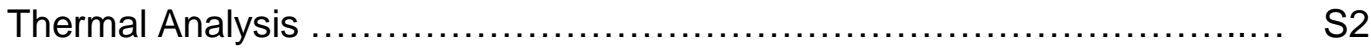

Chemical Characterization ....................................................... S3

Temperature Monitoring of NMR Samples ............................. S3

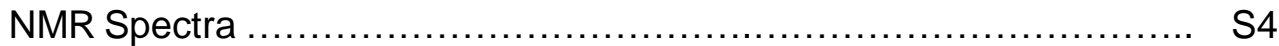

Shear Temperature Sweeps ….............................................. S6

Atomic Force Microscopy ….............................................. S7

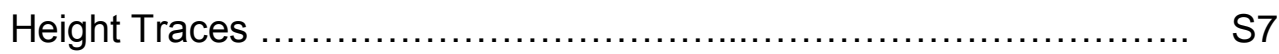

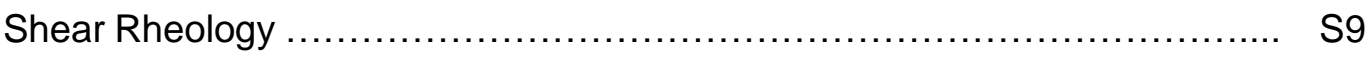

Small Angle Oscillatory Sweeps ......................................... S9

Adhesive Performance Tests ............................................... S11

Shear Adhesion Failure Temperature ................................ S11

Tack Test Results .................................................. S12

Cyclic Tack Results .................................................... S13

Peel Test Results ...................................................... S14

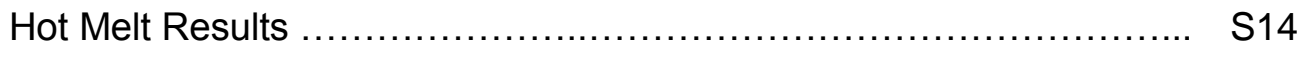

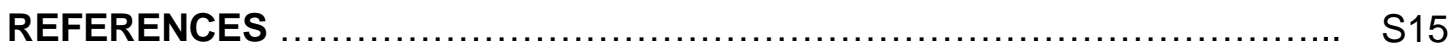




\section{CHARACTERIZATION}

\section{THERMAL ANALYSIS}

a.

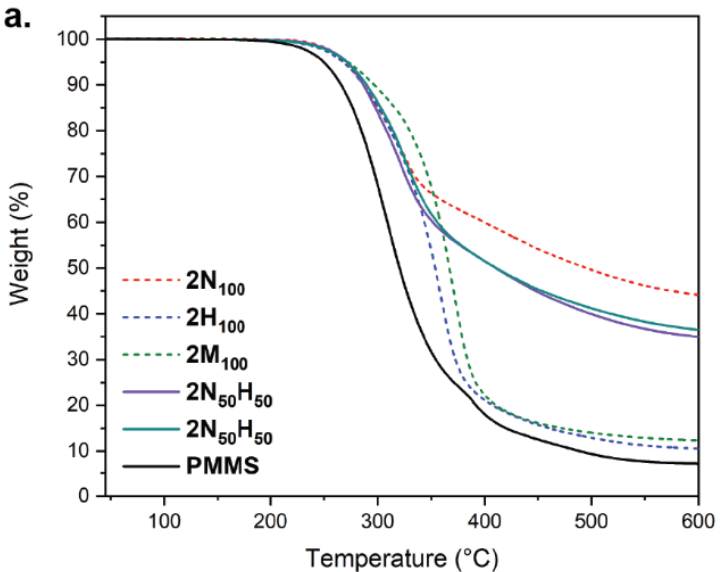

b.

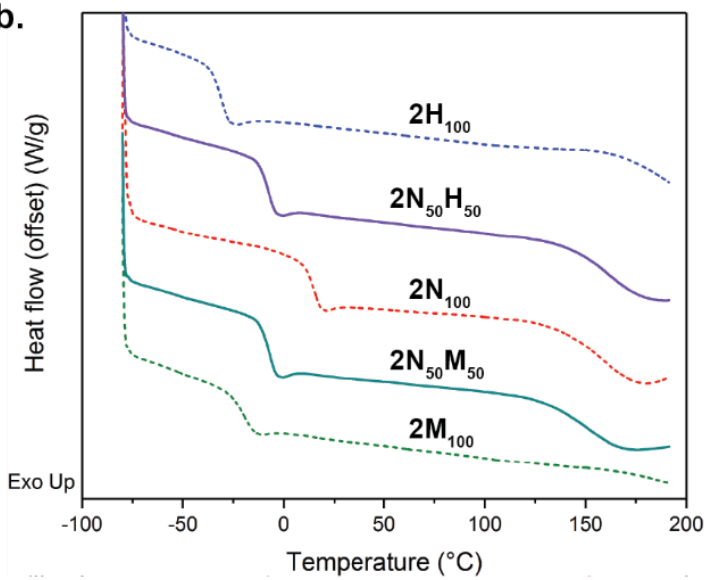

Figure S1. a) Thermogravimetric analysis (TGA) results (ramp rate $=10{ }^{\circ} \mathrm{C} / \mathrm{min}$ to $600^{\circ} \mathrm{C}$ ) demonstrating the films are dry and solvent free. b) Differential scanning calorimetry (DSC) curves for tM films (ramp rate $=10^{\circ} \mathrm{C} / \mathrm{min}$; cool $/$ heat $/ \mathrm{cool} /$ heat cycle $=-20^{\circ} \mathrm{C} / 200^{\circ} \mathrm{C} /-80^{\circ} \mathrm{C} / 20{ }^{\circ} \mathrm{C}$; second heating shown), hybrid materials $\mathbf{2 N}_{50} \mathbf{H}_{50}$ and $\mathbf{2 N}_{50} \mathbf{M}_{50}$ have transitions intermediate of their respective parent networks (note: $\mathbf{2} \mathbf{M}_{100}$ and $\mathbf{2} \mathbf{H}_{100}$ were not mechanically robust enough to form adhesive materials). 


\section{Temperature Monitoring of NMR Samples}

For temperatures at or below $45^{\circ} \mathrm{C}$, a plastic sample spinner was used; for measurements above $45^{\circ} \mathrm{C}$, the sample was held in a ceramic spinner. Sample temperatures were measured by proxy through the use of a neat ethylene glycol standard, using relationships published previously ${ }^{1}$, shown below

$$
\mathrm{T}=466.5-102 \Delta \delta
$$

Where $\mathrm{T}$ is measured in $\mathrm{K}$ and $\Delta \delta$ is the difference between ethylene glycol peaks in ppm.

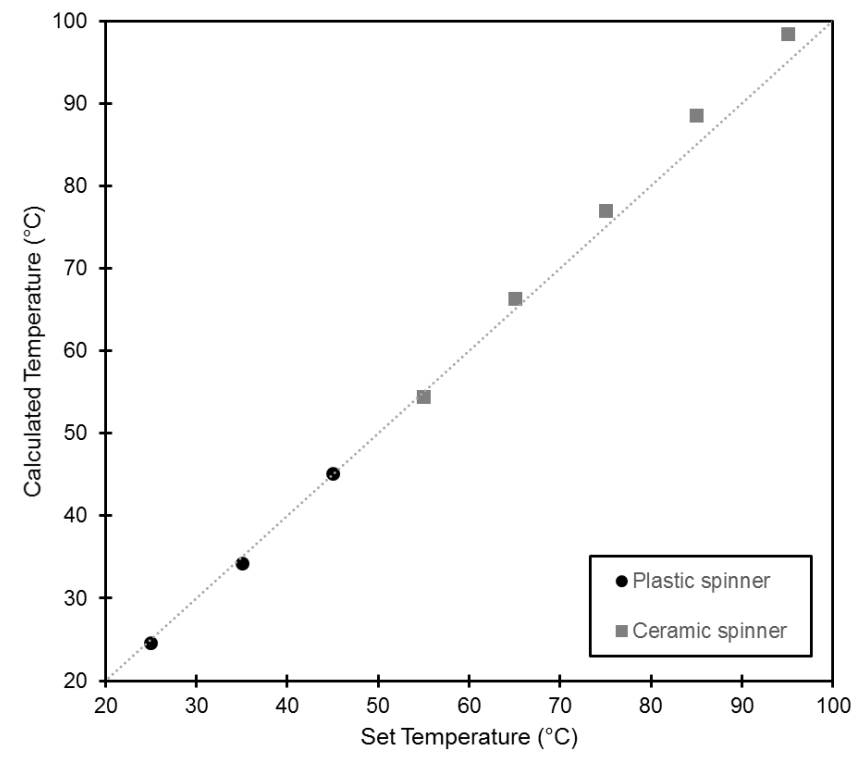

Figure S2. Calculated NMR sample temperatures from a neat ethylene glycol standard, dashed line denotes perfect correlation between set temperature and calculated temperature to highlight deviations at elevated sample temperatures. 
<smiles>[R]c1ccc(C=C(C#N)C(=O)OC)cc1</smiles><smiles>[R]c1ccc([C@H](S[Ga])[C@H](C#N)C(=O)OC)cc1</smiles>
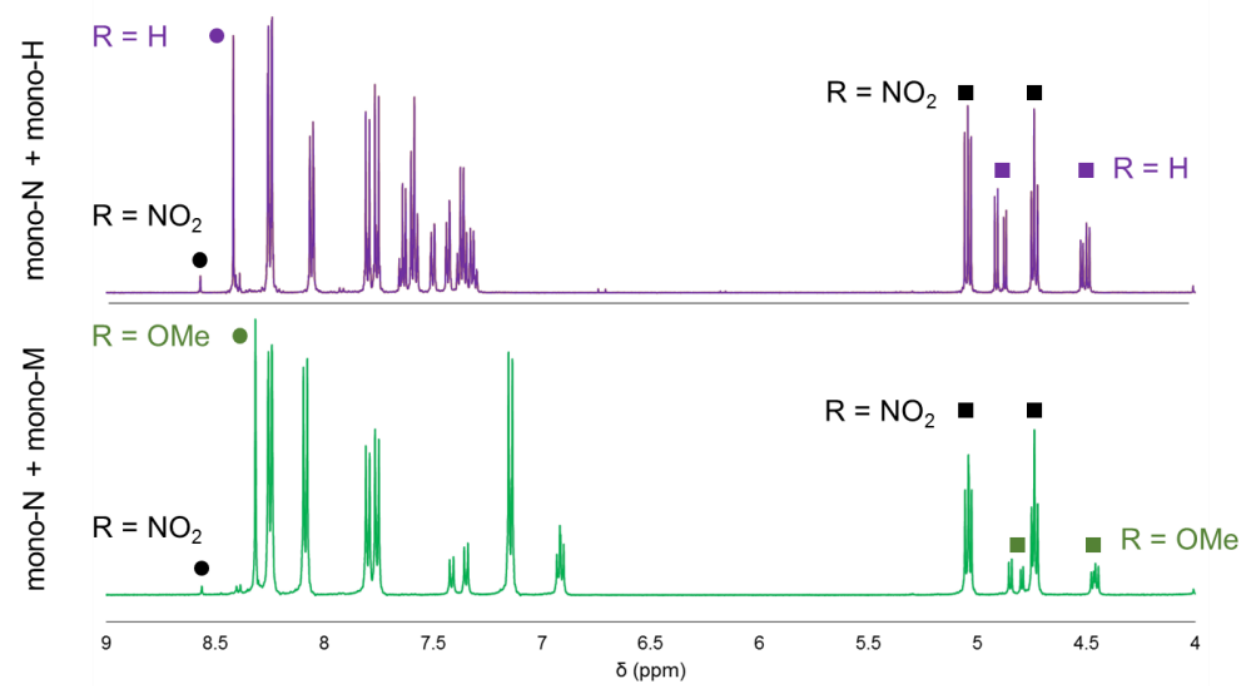

Figure S3. Representative NMR spectra of mono-N and mono-M/H mixtures with 1-octanethiol and peaks used to calculate overall and species-specific association at equilibrium.

fraction $R$ association $=\frac{\int \text { associated } R(\text { square }) \text { peaks }}{\int \text { associated } R(\text { square }) \text { peaks }+2 \int \text { dissociated } R(\text { circle }) \text { peaks }}$

a.

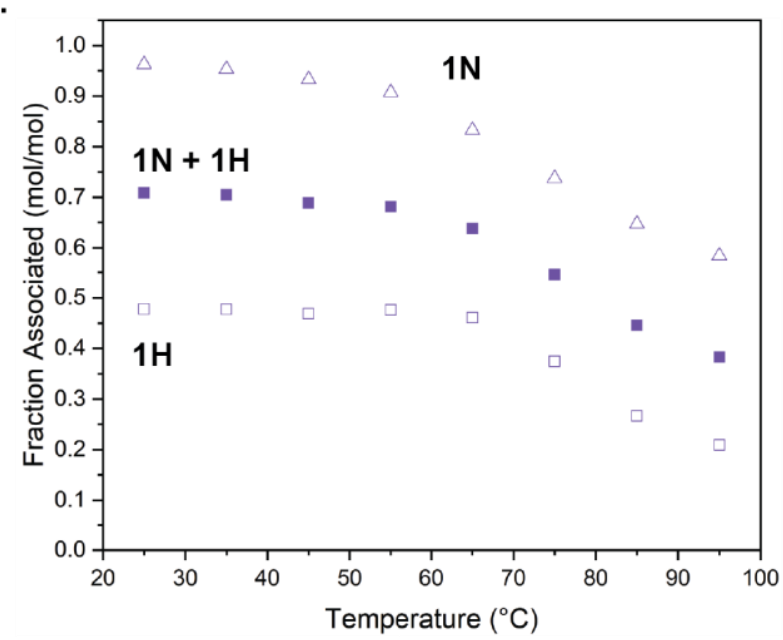

b.

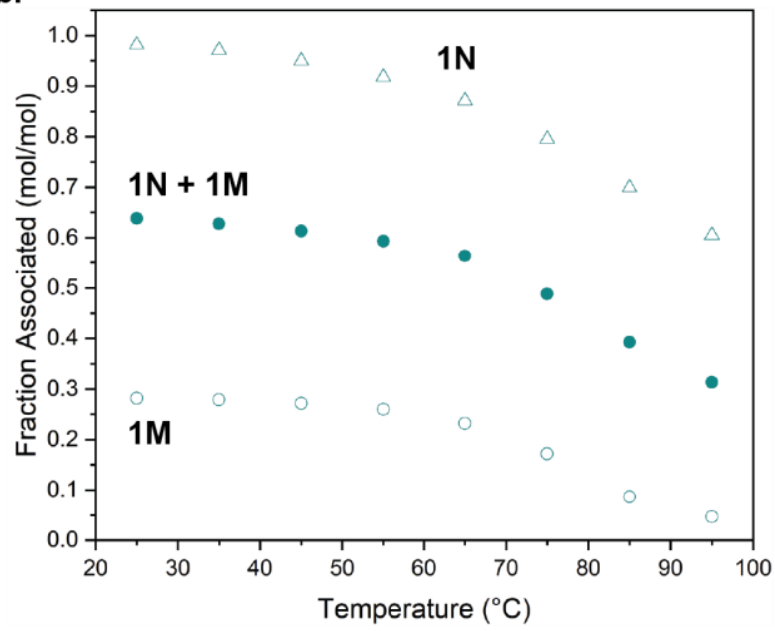

Figure S4. Overall and species-specific equilibrium position of association as a function of temperature for 1:1 mixtures of mono- $\mathbf{N}$ with either a) mono-H or b) mono-M with 1-octanethiol in DMSO-d 6 . 
The data in Figure S4 can be used in conjunction with the following equilibrium reactions<smiles>[X]c1ccc(/C=C(\C#N)C(=O)OC)cc1</smiles>

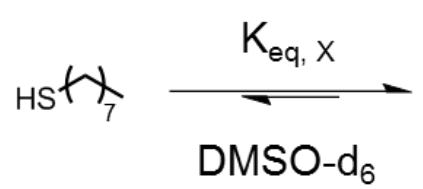<smiles>[X]c1ccc(C(SCC)C(C#N)C(=O)OC)cc1</smiles>

Where $\mathrm{K}_{\mathrm{eq}} \mathrm{x}$ is defined as

$$
\mathrm{K}_{\mathrm{eq}, \mathrm{X}}=\frac{[\text { Bonded } \mathrm{X}]}{[\text { Unbonded } \mathrm{X}][\text { Unbonded thiol }]}
$$

In this work, only mono- $\mathbf{N}$ was measured in a fashion where $\mathrm{K}_{\text {eq }}$ can be determined in a straightforward fashion from the data provided in main manuscript Figure 3.

Consider the competition equilibrium between Michael acceptors, expressed as<smiles>CCSC(c1ccc([N+](=O)[O-])cc1)C(C#N)C(=O)OC</smiles><smiles>[R]OC(=O)/C(C#N)=C/c1ccc([R])cc1</smiles><smiles>COC(=O)/C(C#N)=C/c1ccc([N+](=O)[O-])cc1</smiles><smiles>[R]c1ccc(C(SCC)C(C#N)C(=O)OC)cc1</smiles>

Where $\mathrm{K}_{\text {comp }}$ is defined as

$$
\mathrm{K}_{\text {comp }}=\frac{[\text { Unbonded } \mathrm{N}][\text { Bonded } \mathrm{R}]}{[\text { Bonded } \mathrm{N}][\text { Unbonded } \mathrm{R}]}
$$

As such, $\mathrm{K}_{\mathrm{eq}, \mathrm{m}}$ or $\mathrm{K}_{\mathrm{eq}, \mathrm{H}}$ can be determined

$$
\mathrm{K}_{\mathrm{eq}, \mathrm{R}}=\mathrm{K}_{\mathrm{comp}} * \mathrm{~K}_{\mathrm{eq}, \mathrm{N}}=\frac{[\text { Bonded } \mathrm{R}]}{[\text { Unbonded } \mathrm{R}][\text { Unbonded thiol }]}
$$

Table S1. Calculated equilibrium constants from Figure S4 calculated at $25^{\circ} \mathrm{C}$

\begin{tabular}{ccc}
\hline mono-X & $\mathrm{K}_{\text {comp }}$ & $\begin{array}{c}\mathrm{K}_{\mathrm{eq}, \mathrm{x}} \\
\left(\mathrm{M}^{-1}\right)\end{array}$ \\
\hline$-\mathrm{NO}_{2}$ & - & 1565 \\
$-\mathrm{H}$ & 0.035 & 55 \\
$-\mathrm{OMe}$ & 0.007 & 11 \\
\hline
\end{tabular}




\section{SHEAR TEMPERATURE SWEEPS}

a.

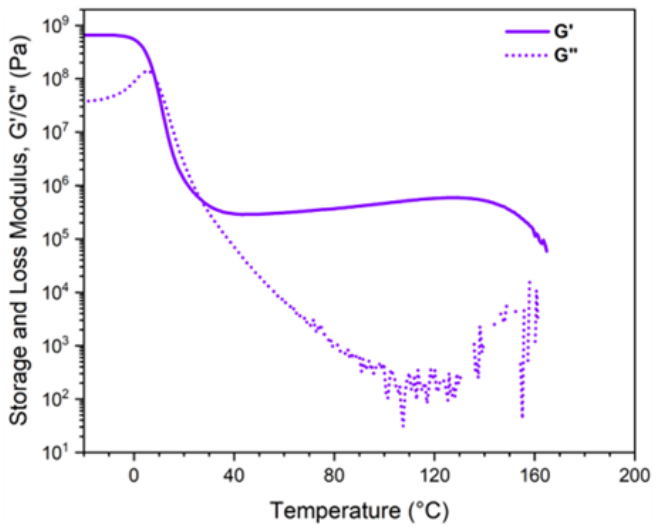

b.

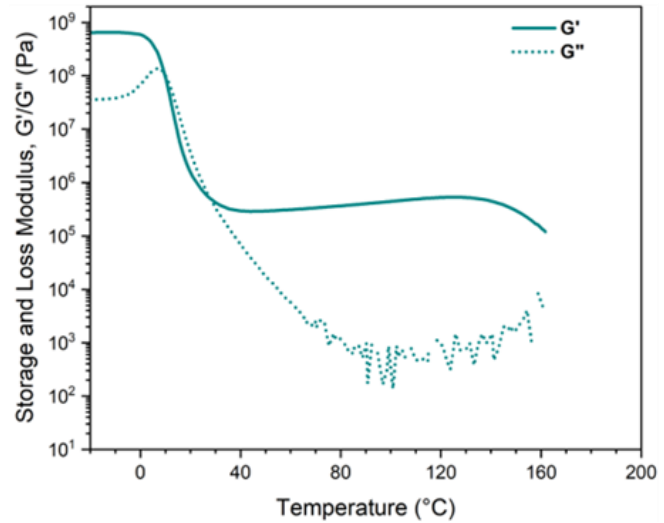

C.

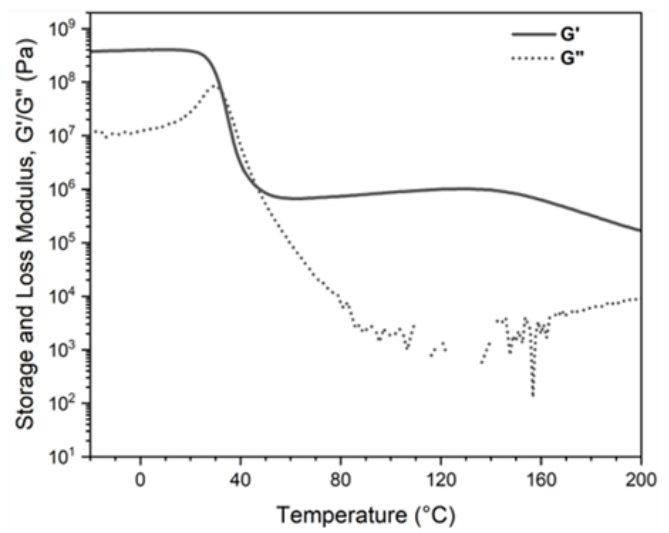

Figure S5. Shear rheometry temperature ramps for a) $\mathbf{2} \mathbf{N}_{50} \mathbf{H}_{50}$, and b) $\mathbf{2} \mathbf{N}_{50} \mathbf{M}_{50}$, c) $\mathbf{2} \mathbf{N}_{100}$, showing storage modulus ( $G$ ', solid) and loss modulus ( $G$ ", dashed). (ramp rate $=3^{\circ} \mathrm{C} / \mathrm{min}$, frequency $=1$ $\mathrm{Hz})$. 


\section{ATOMIC FORCE MICROSCOPY}

\section{Height traces}

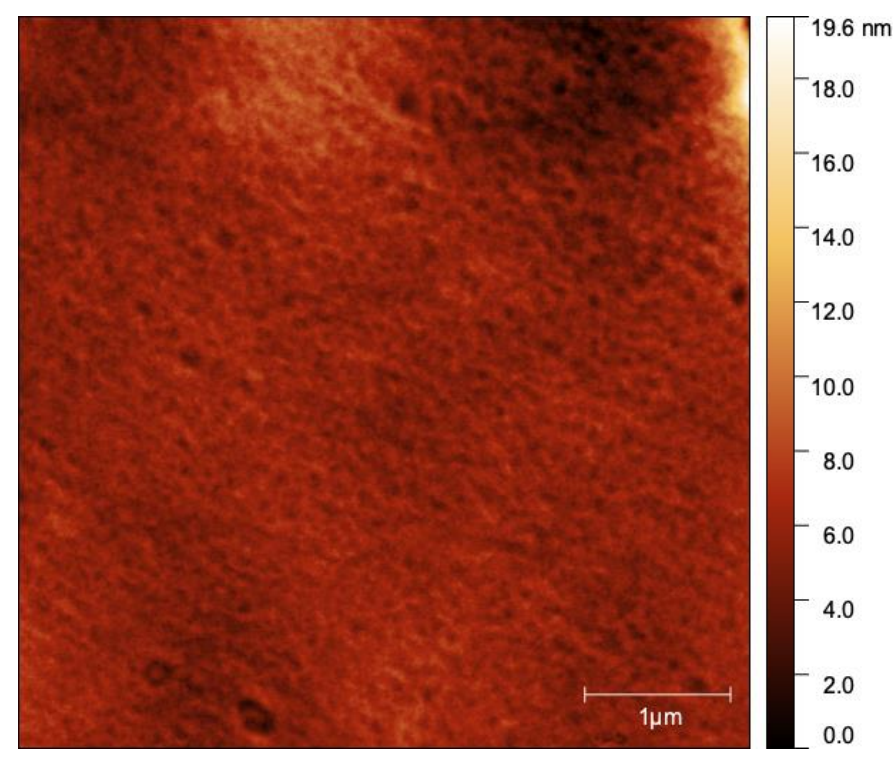

Figure S6. Height trace of $\mathbf{2} \mathbf{N}_{50} \mathrm{H}_{50}$, corresponding to Figure $5 a$ in the main manuscript.

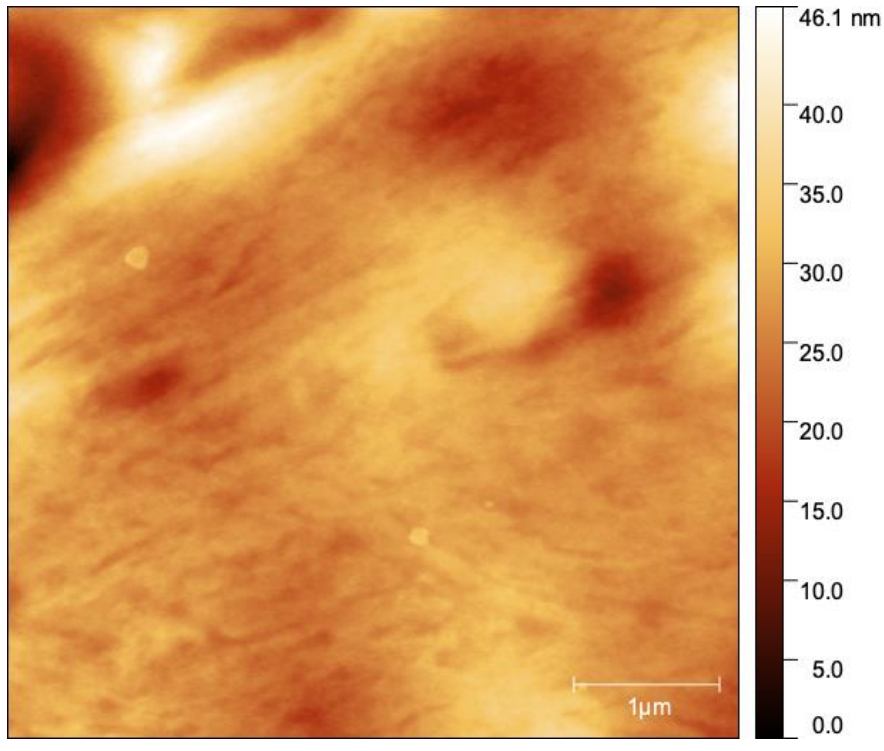

Figure S7. Height trace of $\mathbf{2 N}_{50} \mathbf{M}_{\mathbf{5 0}}$, corresponding to Figure $5 \mathrm{~b}$ in the main manuscript. 


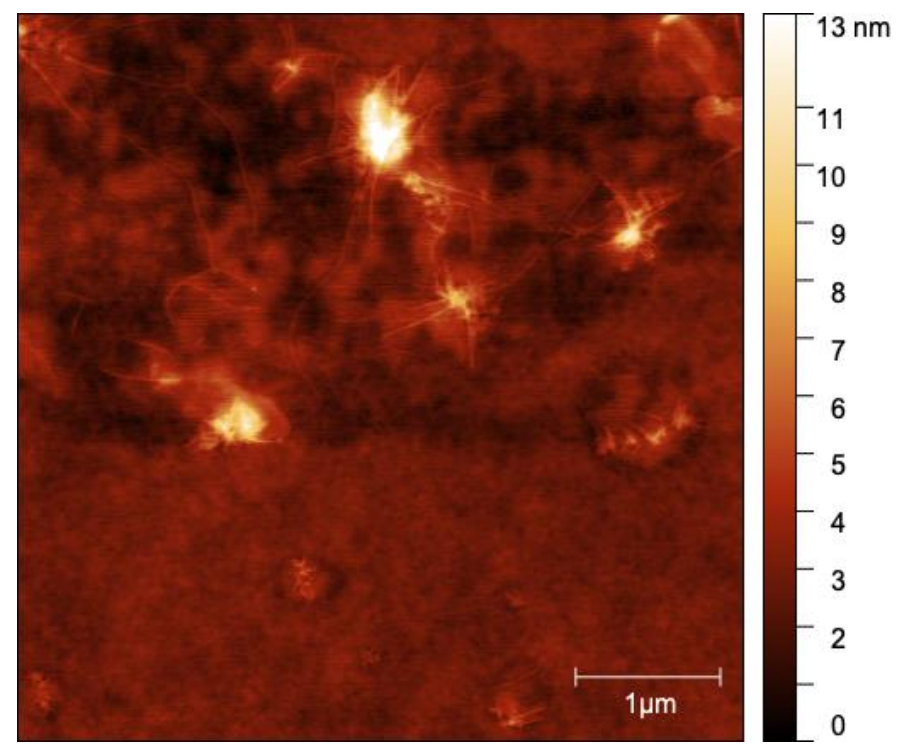

Figure S8. Height trace of $\mathbf{2 N}_{\mathbf{1 0 0}}$, corresponding to Figure $5 \mathrm{c}$ in the main manuscript. (Image processed using a second-order flatten) 
SHEAR RHEOLOGY

Small Angle Oscillatory Sweeps

a.

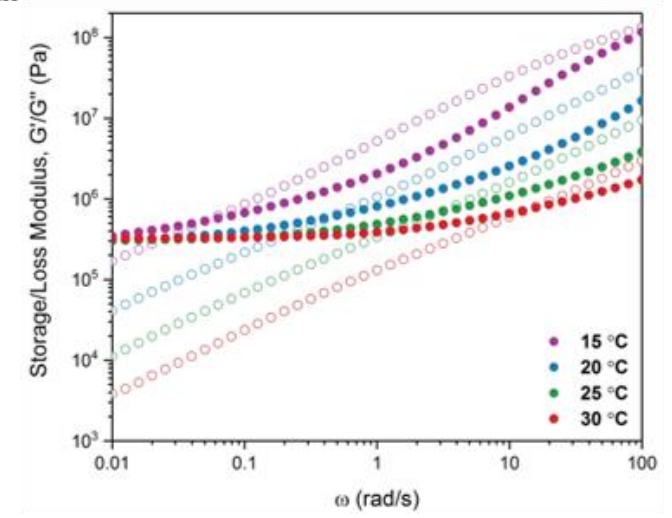

b.

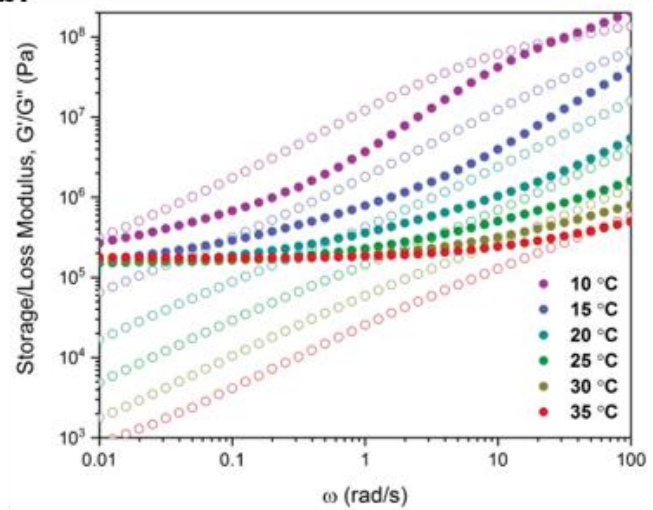

c.

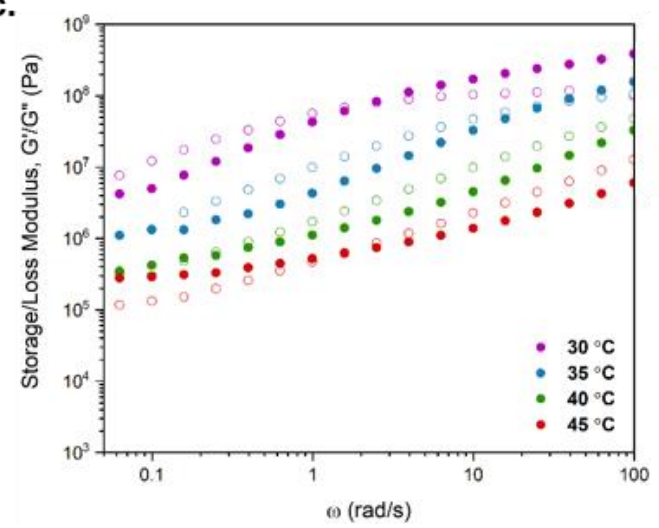

Figure S9. Frequency sweeps at various temperature points for a) $\mathbf{2} \mathbf{N}_{50} \mathrm{H}_{50}$, b) $\mathbf{2} \mathbf{N}_{50} \mathbf{M}_{50}$ and c) $2 \mathrm{~N}_{100}$. 


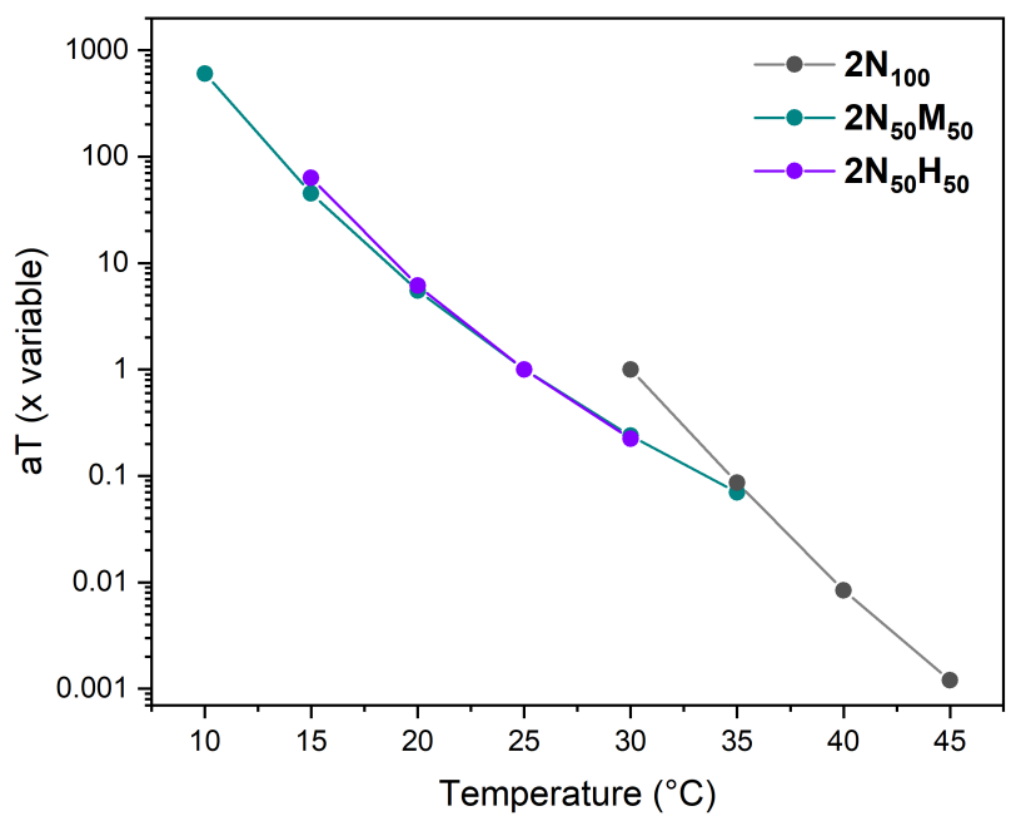

Figure S10. Shift factors following WLF fit for TTS of frequency data.

a.

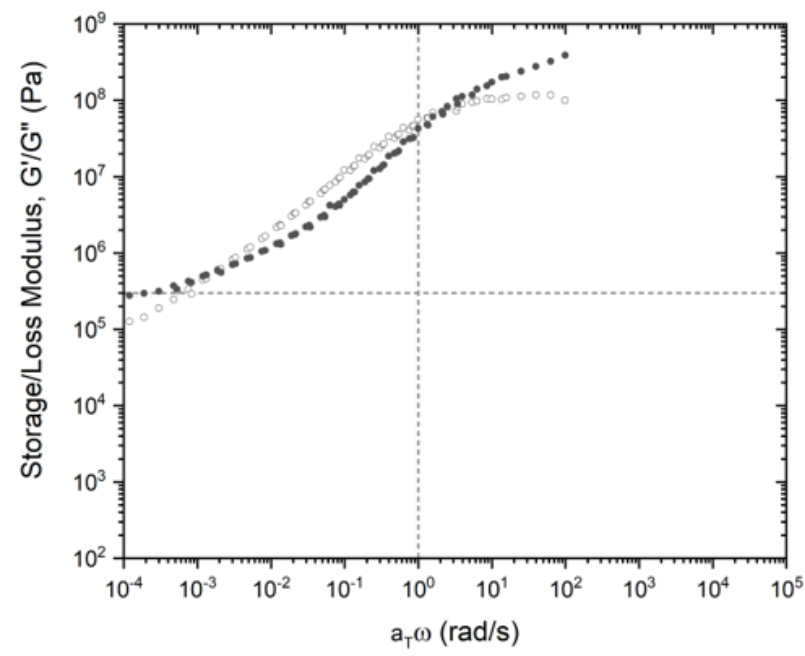

b.

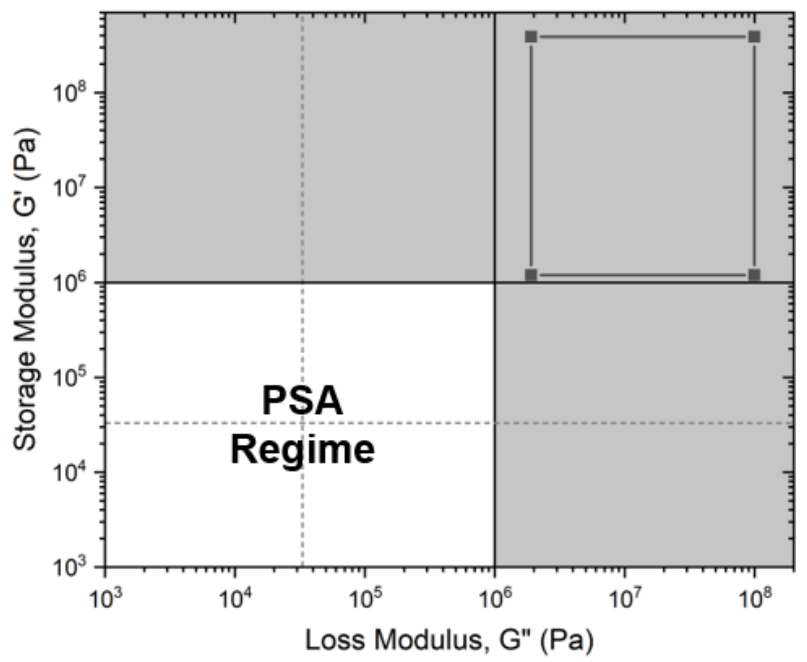

Figure S11. a) Master curve from the WLF temperature shift factor $\left(\mathrm{a}_{T}\right)$ of small amplitude oscillatory shear (SAOS) rheology frequency studies for $\mathbf{2 N}_{100}$ (amplitude (strain) $=1.0 \%$; reference temperature $\left.=30^{\circ} \mathrm{C}\right)$. Dashed lines highlight Dahlquist criterion $\left(3 \times 10^{5} \mathrm{~Pa}\right.$ at $\left.1 \mathrm{rad} / \mathrm{s}\right)$. b) Viscoelastic window for $\mathbf{2 N}_{\mathbf{1 0 0}}$. Gray region highlights moduli outside of typical viscoelastic window plot. 


\section{Shear Adhesion Failure Temperature (SAFT)}
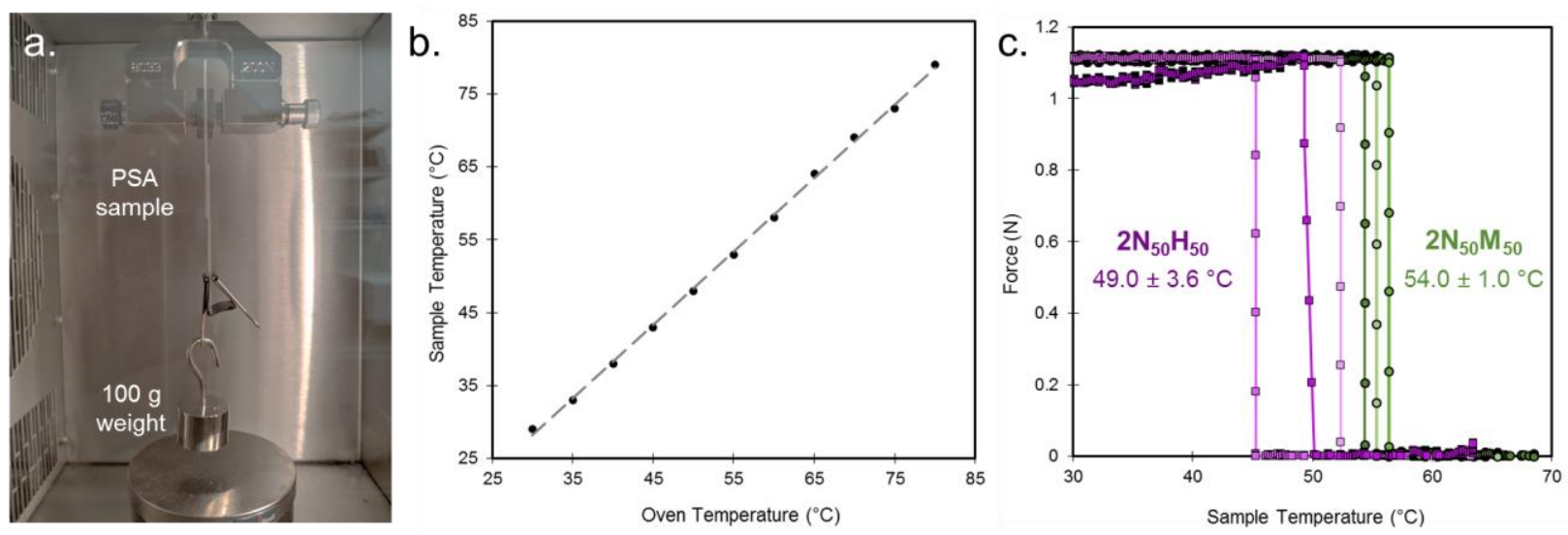

Figure S12. a) Photograph of typical shear adhesion failure temperature test. Briefly, the adhesive sample tape was cut into a strip ca. $20 \mathrm{~mm}$ wide and $40 \mathrm{~mm}$ long. The strip was adhered to a glass microscope slide using a strong cyanoacrylate-based adhesive. The free Kapton surface was removed immediately prior to testing and a second slide was adhered to the thiaMichael adhesive with a weight of $1 \mathrm{~kg}$ for 60 seconds prior to testing. b) Calibration curve of sample temperature (measured via thermocouple clamped between glass slides) as a function of oven temperature. c) Force curves showing the sample temperatures at which the hanging load suddenly drops. Average temperatures and standard deviation reported for 3 experimental runs. 


\section{Tack Test Results}

a.

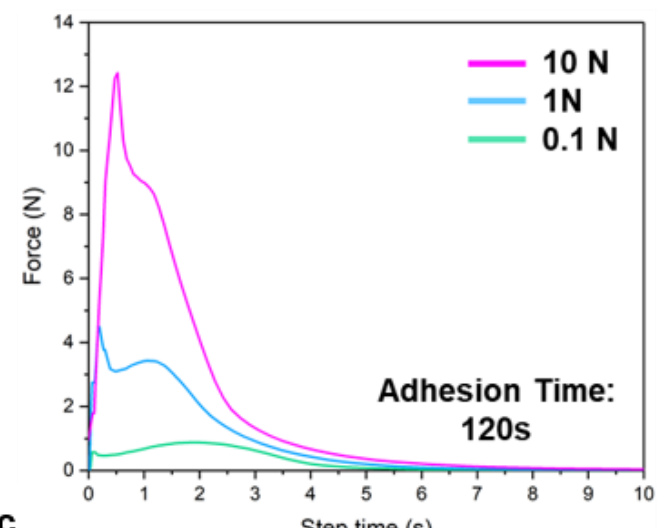

c.

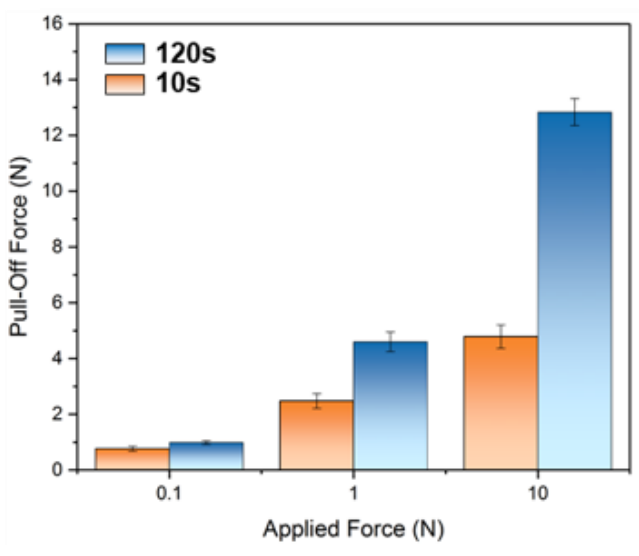

b.
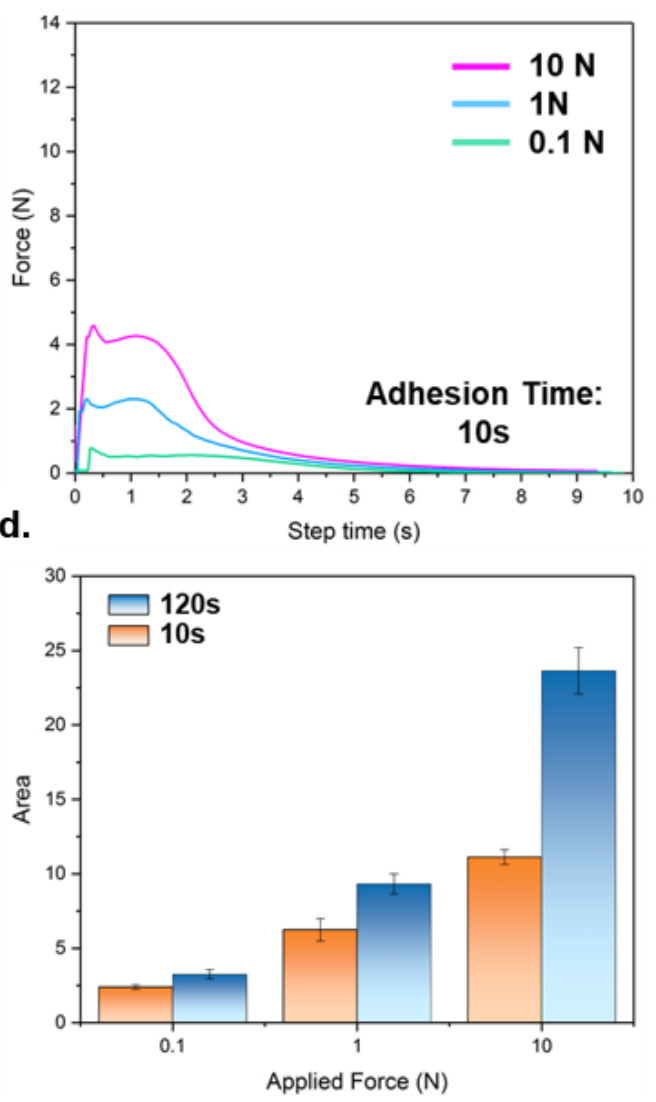

Figure S13. Force curves showing tack test results for $\mathbf{2} \mathbf{N}_{50} \mathrm{H}_{50}$ with different applied forces and adhesion times of A) 120 s and B) 10s. Graphical summary of A) pull-off force and B) area under the curve for tack test of $\mathbf{2 N}_{50} \mathrm{H}_{50}$ at different adhesion times and applied forces. $8 \mathrm{~mm}$ parallel plate and $0.1 \mathrm{~mm} / \mathrm{s}$ strain rate. 

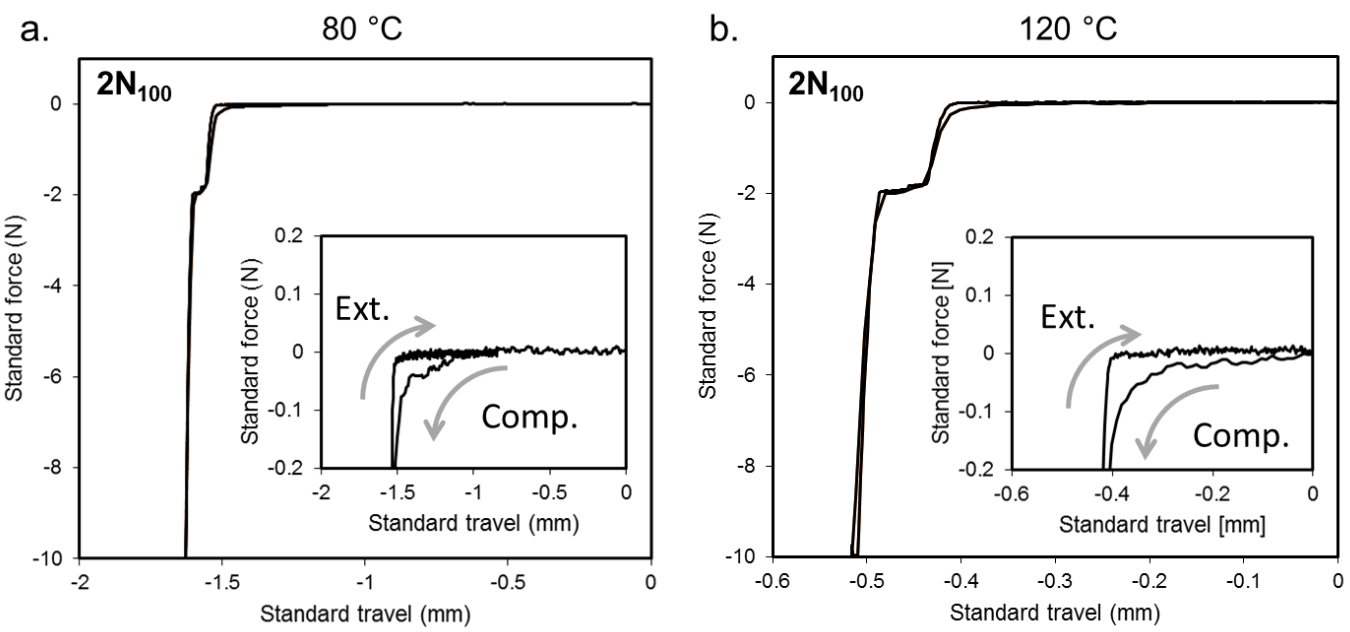

Figure S14. Representative force-extension results for tack tests with $2 \mathrm{~N}_{100}$ at a) $80{ }^{\circ} \mathrm{C}$ and b) $120^{\circ} \mathrm{C}$. Interestingly, neither temperature indicates any measurable adhesion force after the 10 $\mathrm{N}$ compressive loading phase.

\section{Cyclic Tack Results}

a.

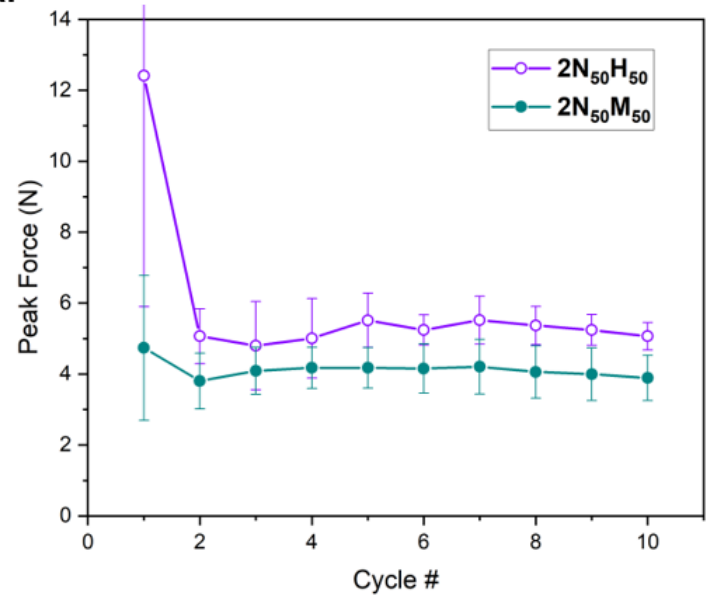

b.

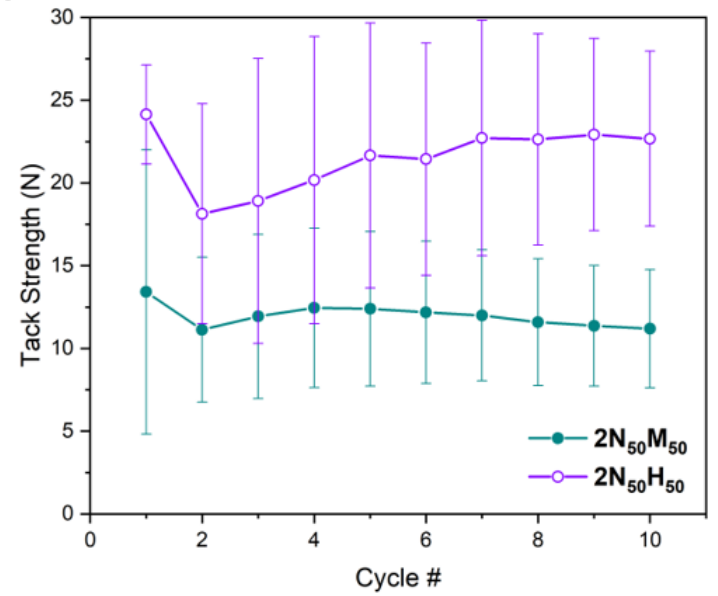

Figure S15. Graphical representation of a) peak force and b) tack strength (area under the curve) for 10 consecutive repeat tack experiments on $\mathbf{2 N}_{\mathbf{5 0}} \mathbf{H}_{50}$ (violet) and $\mathbf{2} \mathbf{N}_{50} \mathbf{M}_{50}$ (cyan). $8 \mathbf{m m}$ parallel plates, $0.1 \mathrm{~mm} / \mathrm{s}$ strain rate, 60 second adhesion time, $1.0 \mathrm{~N}$ applied force. 


\section{Peel Test Results}

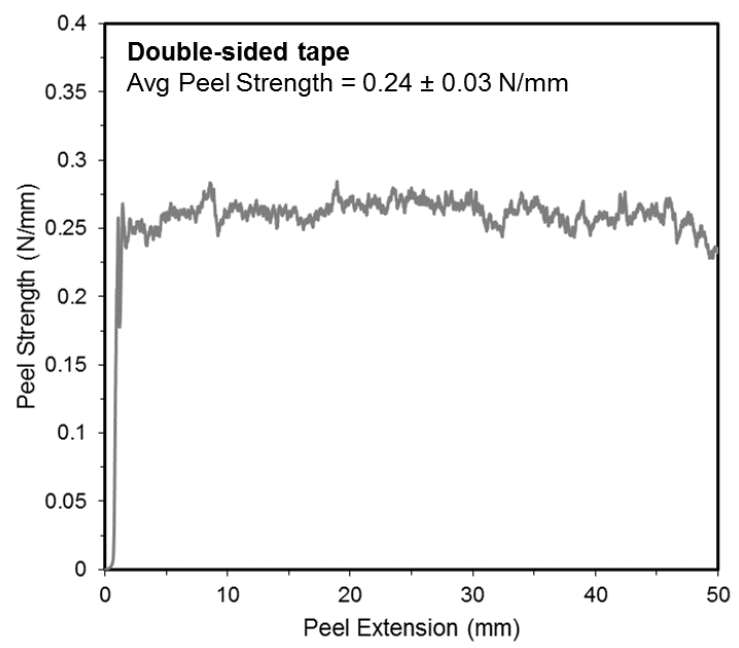

Figure S16. Representative peel test curve for double-sided tape (Scotch 3M).

\section{Hot Melt Results}
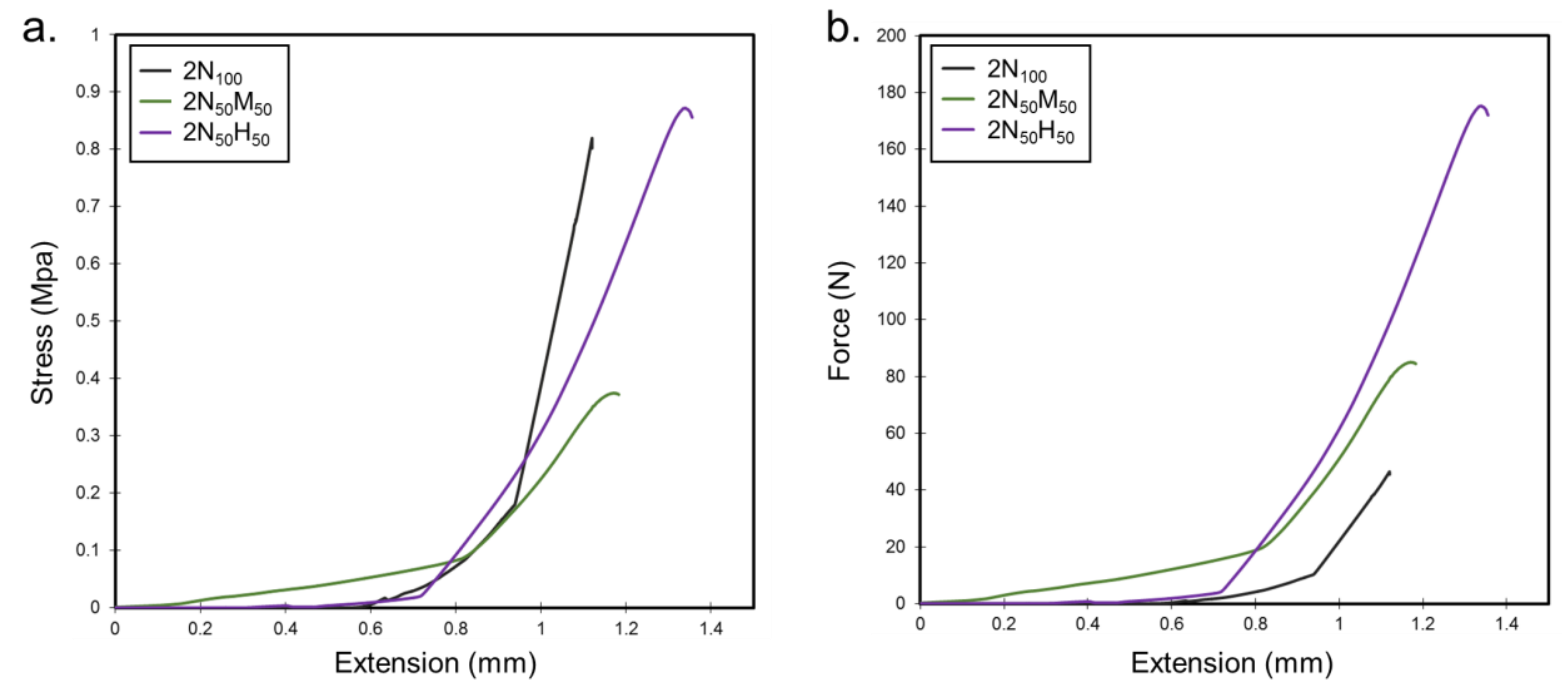

Figure S17. Representative mechanical properties of HMA samples. a) Stress-extension, calculated based on the footprint of the sample after failure (seen in Figure 9b-d). b) Forceextension curves, highlighting the outstanding performance of the hybrid materials (which spread more efficiently than $\mathbf{2} \mathbf{N}_{100}$ ). 


\section{REFERENCES}

(1) Ammann, C.; Meier, P.; Merbach, A. A Simple Multinuclear NMR Thermometer. J. Magn. Reson. 1982, 46 (2), 319-321. 